\title{
NON-SURGICAL MANAGEMENT OF DYSTOCIA DUE TO STERNOPAGUS MONSTER IN MURRAH BUFFALO
}

\author{
A.K. SINGH ${ }^{1}$, M. KUMAR ${ }^{1}$, V. SACHAN ${ }^{* 1}$ AND A. SAXENA ${ }^{1}$ \\ ${ }^{1}$ Department of Veterinary Gynaecology \& Obstetrics, Pandit Deen Dayal Upadhyaya Pashu Chikitsa \\ Vigyan Vishwavidyalaya Evam Go Anusandhan Sansthan, Mathura-281 001, Uttar Pradesh, India

\begin{abstract}
A graded Murrah buffalo at her full gestation was presented with continuous straining since several hours with any progression in process of parturition. On the basis of thorough per vaginal examination, the case was diagnosed as the dystocia due to twin monstrosity. The case was managed by fetotomy in place of cesarean section. Fetus was found a sternopagus conjoint twin monster also confirmed by postmartum examination. Because of post operative care and medicinal therapy, the animal was recovered successfully.
\end{abstract}

Key words: Buffalo, Dystocia, Fetotomy, Monstrosity, Sternopagus monster

Dystocia means inability of dam to deliver a fetus naturally without any difficulty and it leads to the economic losses by reducing calf production, decreased fertility and reduction in milk production with risk to dam morbidity and mortality. Developmental disturbances involving various organs and systems may lead to monstrosities. Maximum frequency of two pregnancies appears from the fifth pregnancy onward in cow and maximum monozygotic pregnancies $(0.24 \%)$ in fourth gestation as well as maximum dizygotic pregnancies $(2.54 \%)$ in fifth gestation (Hafez and Hafez, 2000). Fetal anomalies and monstrosities commonly cause dystocia in bovines along with other livestock. In present case, a rare conjoined twin (sternopagus dicephalus tetrabrachius tetrapus dicaudatus) monster in a Murrah buffalo and successful management by fetotomy is reported.

A seven year old full term pregnant Murrah buffalo in her fourth parity was presented to the Teaching Veterinary Clinical Complex (Kothari Veterinary Hospital), College of Veterinary Science and Animal Husbandry, Pandit Deen Dayal Upadhyaya Pashu Chikitsa Vigyan Vishwavidyalaya Evam Go Anusandhan Sansthan, Mathura, U.P. Animal was anorectic, restless and intermittently straining since last 10 hours but not able to deliver the fetus. There was no previous history of difficult in parturition, retained placenta or dystocia due to fetal monstrosity. Water bags had ruptured about 7 hours before. The case was treated by the local veterinarian for about 1 hour to expel the fetus by using forced traction but failed. The animal was active with moderate straining, loosen sacrosciatic ligament, engorged udders and swollen perineal region. No discharge was found from vulva. Clinical examination revealed rectal temperature $\left(104^{\circ} \mathrm{F}\right)$, pulse $(90 / \mathrm{min}$.$) with congested mucus$ 
membranes. Per vaginal examination revealed fully dilated cervix with lubricated birth canal without lacerations. The fetus was found in posterior presentation with lumbo-ilial position.

Two hind limbs with tail were presented in birth canal. Another two hind limbs with an extra tail were also palpated. Two fetuses were palpated to be attached at thoracic region but head and other extremities were not palpable. Fetuses were considered as sternopagus twin monster and decided to be fetotomed as vaginal delivery by force traction was not possible.

Buffalo was restrained in lateral recumbency and treated with anti-shock therapy inj. Curade $^{\circledR}$ (dexamethasone $40 \mathrm{mg}$, i.m. total dose) along with hemostat inj. Texableed ${ }^{\circledR}$ (tranexamic acid@5 mg/kg b.wt., i.m), antihistaminic inj. Avilin ${ }^{\circledR}$ vet (pheniramine maleate $227.5 \mathrm{mg}$, i.m. total dose), antibiotic inj. Intacef ${ }^{\circledR}$ (ceftriaxone @ $10 \mathrm{mg} / \mathrm{kg}$ b.wt., i.m.) and anti-inflammatory inj. Megludyne ${ }^{\circledR}$ (flunixin meglumine @2.2 mg/kg b.wt., i.m.) was administered before starting the procedure. Low epidural anesthesia $(5 \mathrm{~mL}, 2 \%$ lignocaine hydrochloride) was given to avoid the abdominal straining. After adequate lubrication of birth canal with liquid paraffin, the fetotomy was performed using Thygeson's double barrel fetotome. Detruncation of one fetus was performed at the level of the attachment and the amputated portion of fetus was removed out by force traction applying Moore's obstetrical chain on both hind limbs which were in the birth canal. Remaining twin monster was also relieved out with the help of obstetrical chain and Williams long handle hook by manual covering of the amputated portion in order to protect the birth canal from any damage. Placenta came out along with the fetus. Gross anatomy revealed sternopagus, dicephalic, tetrabrachius, tetrapus and dicaudatus (Fig. 1) having same sex (male) with separate organs (Fig. 2). Following delivery, supportive therapy included 2L Intalyte ${ }^{\circledR}$ saline with 3L normal saline i.v., 50 IU oxytocin, $15 \mathrm{~mL}$ Neurokind plus ${ }^{\circledast}$ i.v. and Cleanex ${ }^{\circledR}$ blous @ 4 boli orally daily for 3 days. Postmortem examination revealed the presence of two separate hearts, two pairs of lungs (some portions were fused), two gall bladders, four kidneys (Fig. 2) and fused liver.

Conjoined twin fetuses are usually originate from single zygote which divides incompletely into two more or less symmetrical components at the primitive streak during embryonic development and develops into twins (Spiers et al., 2010) as thoracopagus. Conjoined twins develop due to improper separation after the development of the embryonic plates (Jerome et al., 2010). Conjoined twins are always identical twins and of the same sex (Sachan et al., 2016) as also found in the present case. Such twins are usually due to non-inherited defects and often lead to severe dystocia (Roberts, 2004). Depending upon the site and extent of fusion, the types of the twins may differ. Various types of monsters cannot be removed without caesarean section most of the time (Gupta et al., 2011). But The animals subjected to caesarean have been found to have less survivability in comparison to those which are subjected to the fetotomy (Singh et al., 2013). Kanisht et al. (2015) has also reported high mortality along with longer first service to conception interval in animals with cesarean operation in comparison to those which are subjected to other mutation operations. Fetotomy may be a good alternative to caesarean operation in cases having sufficient dilated birth canal. Because of unproductive life of the fetal monsters, fetotomy may be taken into consideration for per vaginal delivery. Caesarean section is more costly, time consuming and require more assistance with more aftercare and longer recovery time (Gupta et al., 2017). Fetotomy is more economical and has less chance of complications like retained placenta, metritis, laminitis and is more potential regarding the production ability of the animal. 
Indian Journal of Animal Health, June, 2020

\section{Sternopagus monster- Non surgical management}

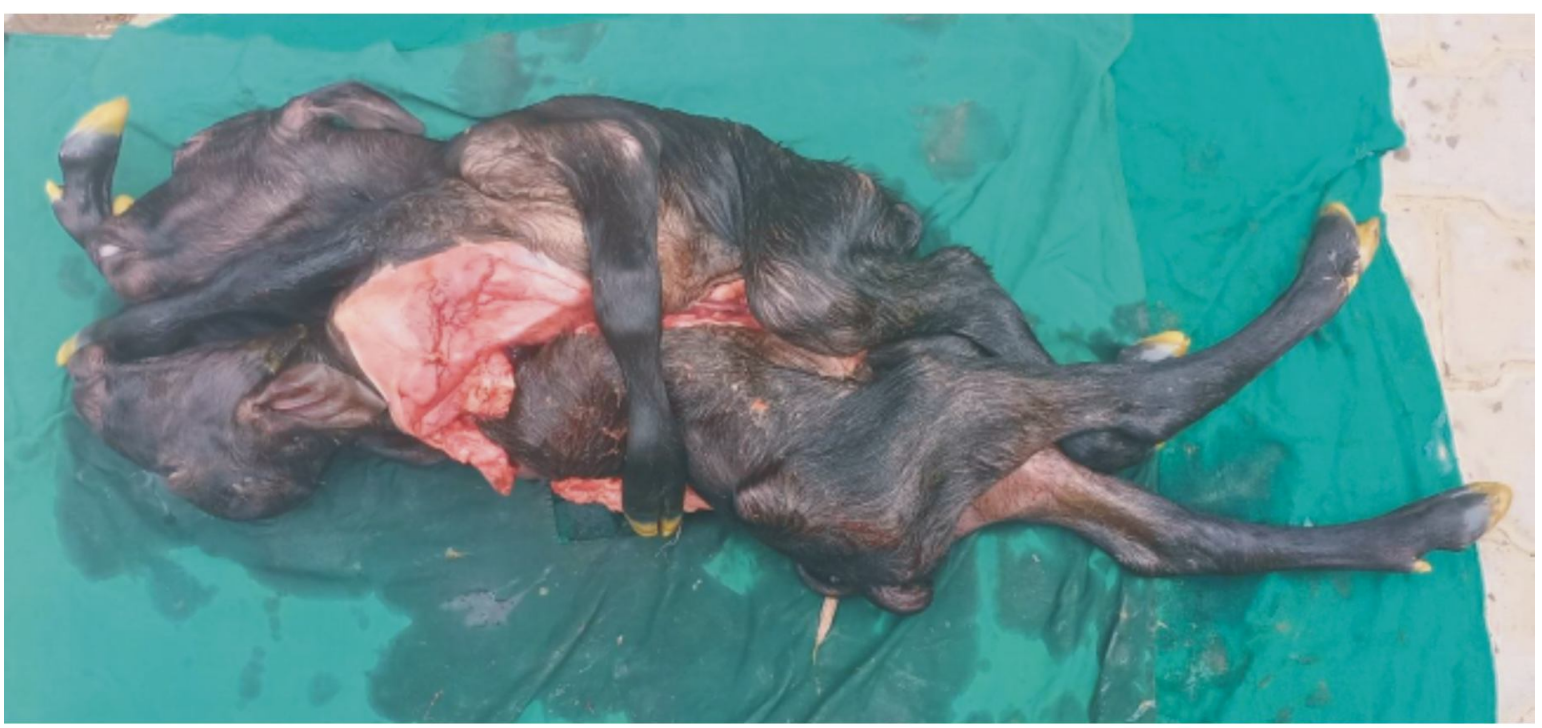

Fig. 1. Sternopagus monster

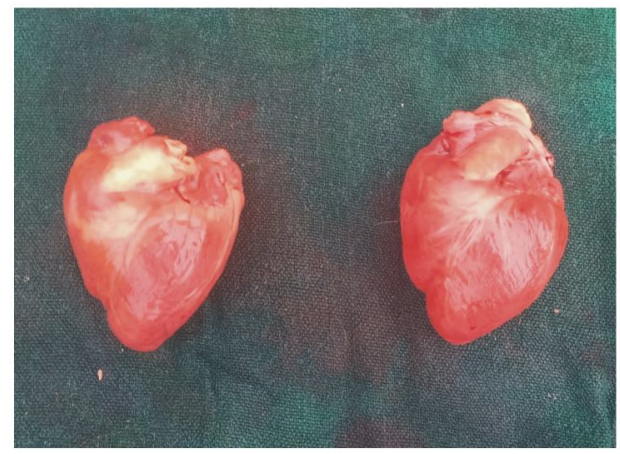

A

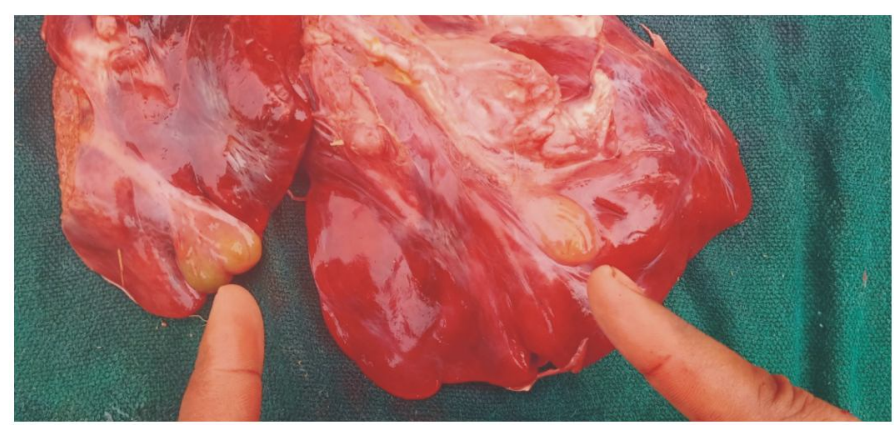

C

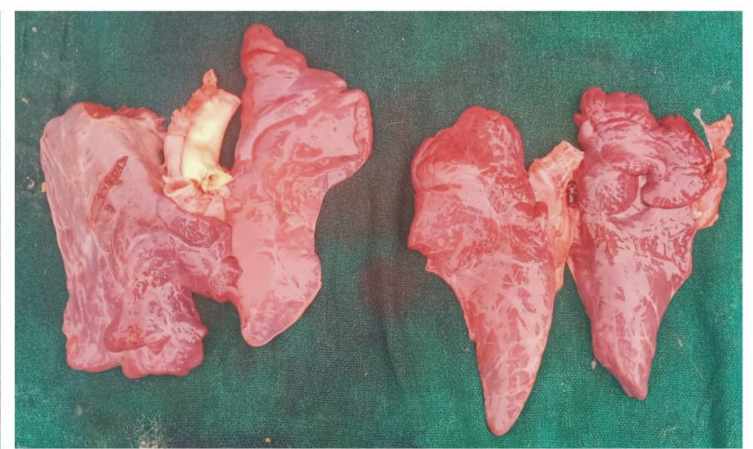

B

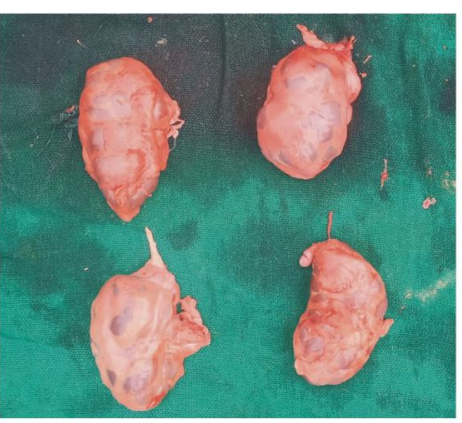

$\mathrm{D}$

Fig. 2. Different organs of twin monster. A. Paired hearts, B. two pairs of lungs, C. separate two gall bladders, D. two pairs of kidnies 


\section{REFERENCES}

Gupta VK, Sharma P and Shukla N, 2011. Dicephalus monster in a Murrah buffalo. Indian Vet J, 88(12): $72-73$

Gupta RK, Singh V, Sachan V, Yadav MK, Yadav DK et al., 2017. Two different obstetrical techniques to manage dystocia due to fetal emphysema in bovine. Indian J Anim Hlth, 56(2): 307-310

Hafez ESE and Hafez B, 2000. Reproduction in farm animals. Wiley-Blackwell, Philadelphia, pp6566

Jerome A, Sarath T and Arunmozhi N, 2010. Dystocia due to a conjoined twin monster in a buffalo. Buffalo Bulletin, 29(3): 229-231

Kanisht B, Tewari A and Chandolia RK, 2015. Incidence of fetal monstrosities in India: A review. Theriogenology Insight, 5(3): 219-229

Roberts SJ, 2004. Veterinary Obstetrics and Genital Diseases, CBS Publishers, New Delhi, India, pp73-74

Sachan V, Kumar B, Sonker V and Saxena A, 2016. Monocephalic thoracopagus tetrabrachius tetrapus monster in buffalo - A case report. Buffalo Bulletin, 35(1): 23-26

Singh G, Pandey AK, Agnihotri D, Chander S, Chandolia RK et al., 2013. Survival and fertility rate in buffaloes following caesarean section and mutation with/without partial fetotomy. Indian J Anim Sci, 83: 251-253

Spiers ZB, Biddle AJ, Gabor MJ, Lee E and Gabor LJ, 2010. Monocephalic thoracopagus tetrabrachius in twin lambs. Can Vet J, 51: 1037-1039 